OPEN ACCESS

ISSN 25482254 (online) ISSN 20893833 (print)

Edited by:

Muhlasin Amrullah

Reviewed by:

Suciati Purwo

*Correspondence:

Lystiana Nurhayat Hakim

tianaghea@gmail.com

Received: 8 November 2020 Accepted: 8 Desember 2020 Published: 10 Desember 2020

Citation:

Hakim LN, Purwaningsih S and

Rachmawati E (2021) Teachers' Strategies In Developing Students'

Critical Thinking And Critical

Reading.

Pedagogia: Jurnal Pendidikan. 10:1. doi: 10.21070/pedagogia.v10vi1i.1

\section{Teachers' Strategies In Developing Students' Critical Thinking And Critical Reading}

\section{Strategi Guru Dalam Meningkatkan Kemampuan Membaca Kritis Dan Berpikir Kritis Siswa}

\author{
Lystiana Nurhayat Hakim $^{1 *}$, Sundari Purwaningsih ${ }^{1}$, Etika Rachmawati ${ }^{2}$ \\ ${ }^{1}$ Pendidikan Bahasa Inggris, Universitas Perjuangan Tasikmalaya, Indonesia, ${ }^{2}$ Pendidikan Bahasa Inggris, Universitas Galuh, \\ Indonesia
}

Critical thinking in the education of Indonesia has not been well socialized; students also tend to accept information without evaluating it first and change ideas uncritically. This case is very detrimental. Therefore, teacher plays an important role in developing students' critical thinking and critical reading ability. The puropse of this study is to find out teachers' strategies in improving students' critical thinking and critical reading ability. This study used qualitative research design, interview and questionaire was used asa research instruments in this study. The results of this study shows strategies used by the teacher are asking open-ended questions, restate and clarify the meaning of a few sentences from the text, and use small group discussions with specific tasks assigned. In short, the teachers' understanding of critical reading and critical thinking is low, their strategy in improving students' critical reading is also limited

Keywords: : Critical Thinking, Critical Reading, Teachers' Strategy

Budaya berpikir kritis padapendidikan di Indonesia belum tersosialisasikan dengan baik bahkan para siswa cenderung tidak antusias untuk merubah ide secara kritis dan cenderung menerima informasi tanpa mengevaluasinya terlebih dahulu. Hal ini tentunya sangat merugikan pendidikan di Indonesia. Strategi guru dalam mengembangkan berpikir kritis dan membaca kritis pada siswanya menjadi hal yang sangat penting. Penelitian ini bertujuan untuk mencari tahu strategi yang dilakukan oleh guru dalam meningkatkan berpikir kritis dan membaca kritis. Penelitian inin menggunakan desain kualitatif dan kuesioner dan wawancara digunakan untuk menjawab pertanyaan peenlitian. Hasil penelitian ini menunjukkan stategi startegi yang digunaka oleh guru diantaranya ialah membri pertanyaan open-ended, mengungkapkan kembali makna pada setiap kalimat pada teks, dan melakukan diskusi kelompok. Dengan demikian dapat disimpulkan bahwa pemahaman guru akan membaca kritis dan berpikir kritis siswa cukup rendah sehingga strategi guru dalam meningkatkan membaca kritis siswa pun masih terbatas.

Keywords: : Critical Thinking, Critical Reading, Teachers' Strategy 


\section{PENDAHULUAN}

Ketersediaan internet sekarang ini sanagat memudahkan siswa untuk memperoleh berbagai macam informasi secara online, hanya dengan mengetik kata kunci saja maka informasi tersebut muncul dengan mudah dari berbagai sumber yang berbeda-beda. Akan tetapi permasalahan mulai hadir ketika siswa menggunakan informasi tersebut secara langsung copy dan paste untuk dijadikan referensi dalam mengerjakan tugas sekolah, tidak melakukan filterisasi informasi, bahkan mereka ikut dalam penyebaran berita hoax. Fenomena copy dan paste pada siswa ialah akibat dari kurangnya berfikir kritis dan membaca kritis, fenomena ini juga didukung dengan karakter siswa di Indonesia yang cenderung tidak antusias untuk bertukar ide dan cenderung menerima ide tersebut tanpa mengevaluasinya terlebih dahulu. Hal ini tentu saja sungguh memprihatinkan dan sangat merugikan dunia pendidikan Indonesia.

Dalam dunia pendidikan di Indonesia pengembangan berpikir kritis pada kurikulum sebelumnya belum tersosialisasikan dengan baik. Namun, sekarang berpikir kritis telah menjadi tujuan pendidikan nasional, hal ini tercantum dalam Peraturan Pemerintah No 17 Tahun 2010 dan didukung dengan kebijakan Menteri Pendidikan dan Kebudayaan yang menyatakan bahwa Kurikulum 2013 memiliki tujuan untuk mengembangkan pembelajaran pasif menuju pembelajaran kritis. Salah satu cara untuk meningkatkan berpikirir kritis ialah dengan membaca kritis. Albeckay (2014) menyatakan bahwa berpikir kritis dan membaca kritis dapat berjalan dengan harmoni, artinya melalui berpikir kritis seorang pembaca akan dapat mengevaluasi, memonitor, dan memahami apa yang dibaca. Selain itu Fadhillah (2017) menyarankan agar mengintegrasikan berpikir kritis pada proses belajar mengajar di kelas perlu dilakukan untuk melatih siswa agar berpikir secara kritis dan menerapkan berpikir kritis dalam kegitaan membaca juga sangaat penting untuk meningkatkan kemampuan siswa dalam mendalami makna dan rasa pada sebuah teks Thamrin et al. (2019).Penelitian terkait dengan berpikir krtitis dan membaca kritis di Indonesia telah banyak dilakukan oleh peneliti sebelumnya diantaranya Indriyana and Kuswandono (2019) yang berfokus pada peningkatan reading comprehension menggunakan strategi HOTS, Rohmah (2018) yang mencari tahu kesulitan siswa, strategi siswa, dan refleski siswa dalam membaca kritis, dan Muhajir et al. (2018) yang mengimplementasikan Inquiry Learning Strategy dalam meningkatakn berpikir kritis siswa. Berbeda dengan penelitian sebelumnya, peneltian ini bertujuan untuk mencari tahu strategi yang telah digunakan guru dalam meningkatkan berpikir kritis dan membaca kritis siswa. Penelitian ini juga penting dilakukan agar dapat membantu pemerintah dalam mengevaluasi ketercapaian pembelajaran berbasis HOTS yang telah dilaksanakan oleh guru di sekolah.

Selama ini dalam pengajaran Bahasa Inggris terutama pada skill membaca siswa hanya membaca teks, mencari kosa kata, serta menjawab soal-soal pemahaman teks saja. Dengan demikian kesempatan siswa untuk berpikir kritis men- jadi terbatas. Maka seperti penjelasan sebelumnya bahwa kunci utama yang dapat meningkatkan berpikir kritis dan membaca kritis siswa ialah guru. Strategi guru dalam mengintegrasikan berpikir kritis dan membaca kritis menjadi poin penting untuk mencapai tujuan pendidikan Indonesia sesuai Permen No 17 Tahun 2010 dan membentuk karakter siswa sebagai generasi bangsa yang unggul. Berpikir kritis merupakan pemikiran reflektif yang mensyaratkan proses pertimbangan dan kehati-hatian terhadap suatu kesimpulan atau informasi. Selain itu berpikir kritis ialah proses mengevaluasi informasi, ide atau proposisi dan mempertimbangkan akibat dari tindakan atau pikiran sebelum menilai apakah ide tersebut masuk akal atau berguna. Pengambilan keputusan terhadap suatu informasi dianggap sebagai bagian dari berpikir kritis. Menurut Halpern (2014) berpikir kritis adalah interpretasi terampil dan aktif serta evaluasi pengamatan dan komunikasi, informasi dan argumentasi, sedangkan Yousefi and Mohammadi (2016) menyatakan bahwa kemampuan berpikir kritis diantarnya kemampuan mempertimbangkan, memhamai, menganalisis, mensintesis, menginterpretasi, dan mengevaluasi.

Dari beberapa pendapat mengenai berpikir kritis dapat disimpulkan bahwa berpikir krtitis merupakan bentuk analisis, evaluasi, interpretasi, generalisasi serta mampu mengambil keputusan terhadap sesuatu. Seorang pemikir kritis akan menyediakan argumen yang rasional serta sumber-sumber yang akurat sebagai bukti ketika berpendapat, dia juga akan fokus pada keputusan untuk percaya atau tidak, pemikir kritis juga dapat mengungkapkan pikiranny secara jelas, dan dalam mengekpresikan idenya akan melihat terlebih dahulu siapa audience-nya dan akan memilih kata-kata yang tepat baginya. Banyak guru berpikir bahwa anak-anak akan mengembangkan kemampuan membaca kritis dan berpikir kritis secara otomatis saat mereka tumbuh dewasa dan menjadi lebih berpengalaman dalam berbagai bidang pengetahuan melalui membaca di sekolah dan melalui hidup itu sendiri, akan tetapi pandangan ini ditentang oleh berbagai orang. Salah satunya adalah Taglieber (2000) yang berpendapat bahwa pemikiran kritis harus dan dapat diajarkan kepada siswa, dan bahwa pada kenyataannya, sekolah bertanggung jawab untuk mengembangkan warga negara untuk memiliki kemampuan berpikir secara kritis. Walaupun berpikir kritis dan membaca kritis sulit untuk diobservasi, diajarkan, dan diukur Muchsonah (2015), peran guru dalam pengembangan berpikir kritis dan membaca kritis siswa menjadi sangat penting karena siswa akan bisa menjadi semakin kritis dalam berpikir dan membaca jika diberikan ruang dan kesempatan untuk mengungkapakn ideide mereka Hassani et al. (2013).

Pengembangan berpikir kritis siswa dapat dilakukan dengan membaca kritis. Membaca kritis berbeda dengan jenis membaca teks lainnya seperti skimming atau scanning yang tidak perlu menggunakan pemikirian yang lebih dalam Thamrin et al. (2019). Membaca kritis dapat didefinisikan sebagai cara untuk melihat sebuah teks dan menganalisis apa yang penulis katakan dan metode apa yang penulis gunakan dalam 
berkomunikasi melalui pesan atau ide di dalam buku tersebut. Untuk membaca kritis berarti membaca analitis, artinya bertanya dan memikirkan tentang bahan bacaan yang ada di depan kita Nasrollahi et al. (2014) Ada tiga prinsip yang berbeda antara membaca kritis dan model pemahaman membaca konvensional. Prinsip pertama adalah bahwa membaca kritis merupakan tantangan dengan orientasi keterampilan berbasis banyak model psikologis kognitif yang menekankan pada kemampuan dasar. Kedua, membaca kritis tidak melihat pembaca sebagai penutur asli atau tidak dalam membaca secara otentik, seperti teks pedagogik, atau sebaliknya. Ketiga, membaca kritis tidak istimewa maksudnya komunikasi penulis akan berkaitan dengan efek tulisannya kepada pembaca. Tujuannya adalah untuk mempertemukan penulis dengan pembaca, untuk memahami skema teks penulis dari makna teksnya Wallace (2003).

Teori berpikir kritis menyatakan bahwa membaca kritis (dan menulis) adalah berpikir kritis diterapkan pada proses membaca dan menulis Mohammadi et al. (2012). Untuk gerakan pemikiran kritis, pembaca kritis mengenali berbagai cara yang terdapat dalam masing-masing teks dan setiap hal yang unik dari kreatifitas seorang penulis yang unik. Kemampuan berpikir kritis dalam membaca diantaranya reasioning (beralasan) dimana siswa diajak untuk mengungkapkan ide atau pendapat dengan kata penghubung because (karena), questioning (mempertanyakan) dimana siswa dituntut untuk bertanya lebih dalam dan tidak berpaku pada teks dan jawaban pertanyaan tersebut akan ditemukan melalui analisis, recognising context (mencari tahu kontek) artinya siswa akan melihat dari berbagai persperktif atau sudut pandang, Predicting the content of the text (memprediski isi teks) dimana siswa dapat membandingkan pengetahuan sebelumnya dengan memprediksi isi teks. Beberapa penelitian juga telah menyimpulkan beberapa strategi dalam membaca kritis diantaranya previewing (pratinjau), contextualizing (kontekstualisasi), outlining (menguraikan) and summarizing (meringkas), questioning (bertanya), reflecting (refleksi), evaluating an argument, (mengevaluasi argument) dan comparing and contrasting related readings (membandingkan dengan apa yang dibaca) (Caffee, 2012). Stretegi lain yang dapat dilakukan ialah dengan menggunakan reading-skill strategies (skimming dan scanning, bertany, mengulas, menggunakan kamus, membaca kembali teks, membuat catatan, mencari informasi utama, membuat parafrase, merangkum, mengevaluasi, membandingkan teks, mengidentifikasi fakta dan opini, dan menggunakan strategi SQ3R) dan meggunakan non-reading strategies (dipaksa untuk membaca, melakukan relaksasi, berdiskusi dengan teman membaca dari bagian yang menarik, dan menggali pengetahuan dan pengalaman siswa Rohmah (2018) .

Pada dasarnya dengan berpikir kritis siswa mampu untuk membaca kritis, sebaliknya melalui membaca kritis siswa mampu untuk berpikir kritis. Seperti yang disampaikan oleh Par (2018) bahwa membaca ialah proses berpikir dan berpikir kritis siswa akan dikembangkan dan dibentuk melalui aktifitas membaca kritis. Oleh karena itu untuk mendap- atkan pemahaman suatu teks lebih mendalam guru harus merangsang kemampuan membaca kritis mereka melalui berpikir kritis. Strategi guru dalam mengembangkan membaca kritis dan berpikir kritis siswa sangat diperlukan mulai dari pre-reading, while reading, dan post-reading. Fahim and Ahmadian (2012) menyebutkan strategi yang dapat digunakan oleh guru ialah annotating (membuat anotasi), inferencing (interferensi), dan summarizing (meringkas). Siswa juga perlu dilatih dan diberikan bantuan untuk memperoleh kemampuan berpikir kritis dan mengadopsi pendekatan kritis melalui penyelesaian masalah di dalam pembelajaran. Dalam kegiatan belajar mengajar beberapa teknik dapat dilakukan seperti guru selalu memberikan kesempatan untuk tanya jawab, melibatkan siswa dalam diskusi dengan topic terbaru, menarik, memotivasi, dan mengikutsertakan seiswa agar terlibat aktif dalam kegiatan pembelajaran. Pada penelitian ini peneliti ingin mencari tahu apakah strategi yang diutarakan oleh penelitian sebelumnya dipakai oleh guru atau sebaliknya guru memiliki strategi terbaru dalam mengembangkan berpikir kritis dan membaca kritis siswa.

\section{METODE}

Sesuai dengan tujuan peneltian maka penelitian ini menggunakan studi kasus, penelitian ini dilakukan pada Tahun 2020 dengan guru-guru Bahasa Inggris di dua Kabupaten di Jawa Barat sebagai responden penelitian ini. Untuk menjawab pertanyaan penelitian, peneliti menggunakan kuesioner dan wawancara sebagai instrument penelitian. Pertanyaan wawancara dan kuesioner tersebut ditujukan untuk mencari tahu strategi guru dalam mengembangakan berpikir kritis dan membaca kritis. Langkah-langkah dalam Penelitian Studi Kasus dimulai dengan satu siklus terdiri dari empat tahapan yang diantaranya ialah pemilihan kasus, pengumpulan data, perbaikan, dan penulisan laporan Sugiyono (2018) .

Pada tahap pemilihan kasus peneliti fokus pada berpikir kritis dan membaca kritis, serta peneliti mengidentifikasi strategi guru dalam pengembangan berpikir kritis dan membaca kritis siswa. Selanjutnya pada tahap pengumpulan data, instrument yang dipakai adalah wawancara dan kuesioner. Wawancara dan instrument digunakan untuk menjawab pertanyaan penelitian. Pada tahap perbaikan (refinement) semua data yang telah terkumpul, dilakukan penyempurnaan atau penguatan (reinforcement) data baru terhadap kategori yang telah ditemukan. Pada tahap akhir yaitu penulisan laporan, setelah semua data diolah dan dianalisis peneliti memaparkan hasil penelitian dan memberikan kesimpulan serta saran terkait temuan yang diperoleh setelah melaksanakan penelitian. Dengan melalui tahapan peneletian diatas peneliti akan memperoleh data mengenai pemahaman guru serta strategi guru dalam mengembangkan berpikir kritis dan membaca kritis siswa.

Analisis data pada penelitian ini juga menggunakan model interaktif Miles et al. (2014), kegiatan analisis terdiri dari tiga 
alur kegiatan yang terjadi secara bersamaan, yaitu reduksi data, penyajian data, dan penarikan kesimpulan atau verifikasi. Pada tahap reduksi data, data diperoleh yang diperoleh dari hasil kuesioner dan wawancara dirangkum, dipilih dan dikategorikan serta data difokuskan pada hal-hal yang sesuai dengan tujuan penelitian. Tahap selanjutnya ialah penyajian data berupa narasi catatan lapangan, narasi catatan hasil wawancara, dan tabel hasil kuesioner, kemudian tahap terakhir ialah membuat kesimpulan dan menjawab pertanyaan penelitian dari data yang telah direduksi dan disajikan.

\section{HASIL DAN PEMBAHASAN}

Sesuai dengan tujuan penelitian dan pertanyaan penelitian, penulis menggunakan kuesioner dan wawancara sebagai instrumen penelitian. Data yang dihasilkan dari penelitian ini ialah startegi guru dalam meningkatkan berpikir kritis siswa dan startegi guru dalam meningkatkan membaca kritis siswa pada Tabel 1 dan Tabel 2

[Table 1 about here.]

(diadaptasi dari Sulaiman (2012); Nasrollahi et al. (2014))

[Table 2 about here.]

(diadaptasi dari Sulaiman (2012); Mohammadi et al. (2012))

Keterangan :

$\mathrm{N}=$ Never

$\mathrm{S}=$ Seldom

Ss $=$ Sometimes

$\mathrm{O}=$ Often

$\mathrm{A}=$ Always

Seperti yang telah dipaparkan sebelumnya bahwa penelitian ini bertujuan untuk mencari tahu strategi guru dalam meningkatkan berpikir kritis dan membaca kritis siswa dan untuk mencari tahu strategi tersebut peneliti menggunakan kuoesiner dan wawancara sebagai instrumen penelitian ini. Berdasarkan data yang diperoleh dari kuesioner latar belakang pendidikan guru ialah $10 \%$ D3, 66\% S1, 19\% S2, dan 5\% S3 dengan pengalaman mengaajar mereka ialah $48 \%$ guru telah mengajar lebih dari 15 tahun, 19\% guru telah mengajar selama 11-15 tahun, $19 \%$ guru telah mengajar selama 6-10 tahun, dan $14,3 \%$ guru telah mengajar selama 1-5 tahun. Terkait dengan pengalaman mereka dalam mengikuti pelatihan, $62 \%$ guru telah mengikuti satu kali pelatihan terkait dengan critical thinking dan critical reading, 19\% guru telah mengikuti 2 kali pelatihan terkait dengan critical thinking dan critical reading, dan $19 \%$ guru belum pernah mengikuti pelatihan terkait dengan critical thinking dan critical reading.

Selanjutnya berdasarkan data pada Tabel 1 terlihat bahwa strategi yang paling banyak digunakan oleh guru dalam meningkatkan berpikir kritis siswa ialah dengan memberikan pertanyaan open-ended questions, meminta siswa untuk menggunakan hal-hal yang telah mereka pelajari sebelumnya ke dalam hal yang baru mereka pelajari, meminta siswa untuk menganalisis materi ajar dengan cara membandingkan, mengidentifikasi, membuat persamaan dan perbedaan, meringkas, serta membuat kesimpulan, memberikan pertanyaan yang dapat membuat siswa berfikir kritis untuk menilai sebuah masalah, menciptakan suasana agar siswa mau bertanya, dan menggunakan teknik pembelajaran kooperatif seperti diskusi dan kerja kelompok. Data dari kuesioner ini didukung dengan data hasil wawancara yang dilakukan pada beberapa responden. Selain strategi tersedia pada kuesioner guru pun memiliki strategi lain dalam meningkatkan berpikir kritis siswa diantaranya ialah dengan memberi tugas siswa untuk mencari teks dengan tema yang berbeda lalu mempresentasikan hasil analiasis teksnya dan didiskusikan dengan teman-temanya. Selain itu, guru juga memberikan pertanyaan dan gambar, memberikan aktifitas menebak topik, membandingkan teks, menyelesaikan suatu masalah dalam kelompok belajar, dan memberikan aktifitas debat pada siswa.

Strategi yang telah dilakukan oleh guru dalam meningkatkan berpikir kritis siswanya sudah cukup baik, namun strategi yang dilakukan dirasa guru belum secara maksimal menghasilkan para pemikir kritis di kelas, siswa masih ada yang tidak aktif terlibat dalam diskusi dan mereka tidak mampu untuk menjawab pertanyaan yang disampaikan guru dan teman sejawatnya. Hal ini dikarenakan teknik questioning yang dilakukan oleh guru. Browne and Keeley (2007) mengatakan bahwa pertanyaan yang kritis menyediakan stimulus dan arahan untuk berpikir kritis, menggerakan pikiran kepada pendapat, keputusan, serta penilaian yang lebih baik dan mendalam. Mereka juga menambahkan jika orang pemikir kritis memiliki peran untuk menyuarakan kejanggalan dengan memberikan argumen terkait informasi yang hilang, informasi yang perlu ada, atau pada alasan penulis/penutur dalam menyediakan sebuah teks. Disamping itu, pengalaman serta pengetahuan siswa akan topik yang dibahas terbatas, maka guru dapat melakukan pemberian pengetahuan terlebih dahulu baik menngunakan video, cerita, dan gambar. Guru juga berpendapat bahwa budaya literasi siswanya masih sangat rendah, sehingga strategi berpikir kritis yang dilakukan kadang membuat siswanya bingung. Berdasarkan pernyataan guru tersebut maka peneliti juga menyimpulkan bahwa tanpa adanya budaya literasi yang baik pada siswa maka kemampuan untuk berpikir kritis siswa pun tidak akan meningkat, dan budaya literasi tanpa disertai dengan membaca kritis pun maka kemampuan berpikir kritis siswa akan tetap sama.

Terkait strategi yang digunakan dalam meningkatkan membaca kriris, data pada Tabel 2 menunjukkan bahwa strategi yang selalu digunakan guru untuk meningkatakn membaca kritis siswa ialah dengan cara mengucapakan kembali dan menerangkan makna beberapa kalimat pada sebuah teks, meminta siswa untuk menulis pertanyaan pada setiap paragraph sebuah teks, dan menggunakan teknik skimming atau membaca sekilas untuk mencari ide utama. Dari 10 stategi yang disediakan pada kuesioner, rata-rata responden menunjukkan bahwa mereka tidak rutin melakukan strategi terse- 
but, dengan demikian aktiftas membaca kritis pada siswa tidak sering dilakukan oleh guru. Akan tetapi guru juga memiliki strategi lain dalam meningkatkan kemampuan membaca kritis siswa diantarnya ialah dengan cara memberikan kuis "agree or disagree", mengajak siswa untuk membedakan informasi fakta dan opini, menggunakan gambar untuk melihat persamaan dan perbedaan informasi yang berhubungan dengan teks yang dibaca. Hasil lain yang ditemukan dalam penelitian ini ialah kurangnya pehaman guru terhadap beripikir kritis dan membaca kritis dan strategi yang digunakan dalam membaca kritis dan berpikir kritis. Dari hasil wawancara yang dilakukan responden menjawab dengan kurang tepat terkait pengertian membaca kritis dan berpikir kritis.

"...critical reading adalah teknik menemukan informasi dan gagasan yang terdapat pada texts."

“... metode penyampaian materi reading dengan cara pendalaman pemahaman isi secara rinci dimana siswa diharapkan dapat menemukan informasi secara rinci baik isi maupun gramatikal dalam teks bacaan tersebut."

"...critical reading merupakan suatu metode pembelajaran $r$ eading dengan cara skimming reading dimana siswa-siswi dapat mendapatkan informasi secara rinci baik isi maupun gramatical dalam texts bacaan."

"...teknik menemukan informasi yang tersurat dan tersirat dan gagasan yang terdapat dalam teks."

Berdasarkan pemahaman guru mengenai membaca kritis diatas, penulis menyimpulkan bahwa sebagian besar guru bahasa Inggris tidak memahami metode membaca kritis dalam pengajaran bahasa Inggris. Selanjutnya, dalam menjawab pertanyaan mengenai strategi yang dilakukan dalam meningkatkan berpikir kritis dan membaca kritis pun responden menjawab dengan kurang tepat, strategi-strategi yang diutarakan ialah strategi membaca biasa dengan menggunakan aktifitas skimming dan scanning, menggunakan pendekatan komunikatif, memberikan beberapa kata dan frase dan meminta siswanya untuk membuat kalimat, serta meminta siswa untuk presentasi. Bagi guru yang pernah mengimplementasikan membaca kritis, mereka memberikan pemaparannya sebagai berikut:

“... melalui teknik pembelajaran membaca yang menekankan peserta didik untuk berfikir kritis, memberi opini pribadi terhadap suatu permasalahan yang terdapat dalam bacaan, menghubungkan permasalahan yang terdapat dalam bahan bcaan dan dengan kehidupan sehari-hari, serta memberi solusi terhadap permasalahan tersebut." Berdasarkan pemaparan diatas guru tersebut telah menggunakan membaca kritis dengan benar, dimana dia memberikan kebebasan bagi siswanya untuk berpendapat, bahkan kritikan dan solusi terhadap tulisan yang mereka baca. Selain itu ada juga guru yang mengimplementasikan membaca kritis dengan kurang tepat seperti pemaparannya di bawah ini:

"mengajar reading dengan cara siswa diberikan keleluasaan memahami bacaan secara mendetail baik isi atau gramaticalnya. Pemahaman isi paragrap kemudian pemahaman keselu- ruhan. Pada saat yang sama juga dibahas tentang gramatical kalimat-kalimat yang ada pada text tersebut."

"mengajar reading dengan cara siswa diberikan keleluasaan memahami bacaan dengan mencari difficult word."

Berdasarkan pemaparan diatas para guru tidak mengimplementasikan membaca kritis melainkan reading comprehension atau membaca pemahaman dalam pengajaran bahasa Inggris. Dalam prakteknya guru hanya mengajak siswa untuk memahami isi bacaan tersebut dengan mencari tahu katakata yang tidak dimengerti siswa serta dengan membahas grammarnya saja tanpa membiarkan siswa berpendapat atau mengkritisi bacaan tersebut. Bahkan mereka tidak pernah mengimplementasikannya dan sebagian dari mereka keliru dengan mengimplementasikan reading comprehension atau membaca untuk memahami dengan membaca kritis. Tidak sedikit dari mereka yang menggunakan langkah-langkah reading comprehension seperti mencari kata-kata yang sulit dipahami dan mengecek gramaticalnya. Lalu mereka menyuruh siswanya menjawab pertanyaan berdasarkan teks yang mereka baca. Hal ini sangat bertolak belakang dengan konsep terakhir dari pembahasan membaca kritis yang dilihat dari perspektif literasi kritis sosial.

Hasil penelitian bertolak belakang dengan apa yang dikatakan Wallace (2003); Muchsonah (2015) bahwa dalam konteks bacaan bahasa Inggris sebagai bahasa asing (EFL) tahapan membaca ke dalam beberapa kegiatan, yaitu: pramembaca, proses membaca-, dan pasca-membaca. Pada tahap pra-membaca, siswa akan mendapatkan beberapa pertanyaan seperti mengapa topik ini ditulis, bagaimana topik ini ditulis, dengan cara apa topik ini ditulis, kepada siapa topik ini ditulis dan apa topiknya. Strategi dalam fase proses membaca akan mencakup antara lain menawarkan kepada siswa teks bacaan alternatif, menyusun tugas-tugas yang menawarkan pembaca kemungkinan lebih dari satu cara membaca teks; mengidentifikasi wacana paralel seperti mengidentifikasi orang, tempat, negara, atau fenomena yang dijelaskan, penggunaan penulis bahasa yang mendukung satu orang atau kelompok sosial atas yang lain; dan menganalisis pilihan linguistik yang meliputi menggambar pada berbagai pilihan bahasa yang dibuat oleh penulis untuk membantu membangun wacana yang mencerminkan keyakinan dan nilainilai, yang mengasumsikan berbagai model bacaan bagi para pembaca. Bagi guru yang telah mengimplementasikan membaca kritis, mereka sulit untuk memotivasi siswa agar mengungkapkan pendapat mereka dengan bebas. Oleh sebab itu tidak jarang kegiatan belajar mengajar menjadi jenuh. Hal ini dapat diakibatkan kesalahan guru dalam menggunakan lagkah-langkah membaca kritis yang tidak sesuai dengan teori critical reading sebenarnya.Hal ini tentunya semakin memperkuat penulis untuk menyimpulakan bahwa gurukurang dalam pengetahuannya mengenai membaca kritis. 


\section{KESIMPULAN}

Penelitian ini bertujuan untuk mencari tahu strategi guru dalam meningkatkan kemampuan berpikir kritis dan membaca kritis siswa. Dengan menggunakan metode studi kasus serta kuesioner dan wawancara sebagai insrumen penelitian, maka hasil penelitian ini dapat disimpulkan bahwa pemahaman guru akan membaca kritis dan berpikir kritis siswa cukup rendah, strategi guru dalam meningkatkan membaca kritis siswa pun masih rendah, guru tidak selalu melakukan kegiatan peningkatan berpikir krits dan membaca kritis dalam kegiatan belajar mengajarnya. Berbeda dengan penelitian sebelumnya, hasil peneilitian ini menujukkan hal yang berbeda dimana guru memliki pemahaman akan berpikir kritis dan membaca kritis yang rendah sehingga strategi

\section{REFERENCES}

Albeckay, E. M. (2014). Developing Reading Skills through Critical Reading Programme amongst Undergraduate EFL Students in Libya. Procedia - Social and Behavioral Sciences 123, 175-181. doi: 10.1016/j.sbspro.2014.01.1412.

Browne, M. N. and Keeley, S. M. (2007). Asking the Right Questions: A Guide to Critical Thinking. vol. 40. 1-240. doi: https://doi.org/10.1002/1521-3773.

Fadhillah, A. M. (2017). Embedding Critical Thinking Through Critical Reading : Teaching Narrative Text. Journal of English and Education 5, 92-102.

Fahim, M. and Ahmadian, M. (2012). Critical Thinking and Iranian EFL Context. Journal of Language Teaching and Research 3, 128-135. doi: 10.4304/jltr.3.4.793800.

Hassani, M. T., Rahmany, R., and Babaei, M. (2013). The Relationship between Iranian EFL Learners' Critical Thinking and Reading Comprehension Performance in Journalistic Texts. Theory and Practice in Language Studies 3, 1873-1878. doi: 10.4304/tpls.3.10.1873-1878.

Indriyana, B. S. and Kuswandono, P. (2019). Developing Students' Higher Order Thinking Skills (HOTS) in Reading: English Teachers' Strategies in Selected Junior High Schools. JET (Journal of English Teaching) 5, 204-204. doi: 10.33541/jet.v5i3.1313.

Miles, M. B., Huberman, A. M., and Saldana, J. (2014). Qualitative Data Analyisis: A Mathods Sourcebook (United State of America: SAGE Publications, Inc).

Mohammadi, E. N., Heidari, F., and Niry, N. D. (2012). The Relationship between Critical Thinking Ability and Reading Strategies used by Iranian EFL Learners. English Language Teaching 5, 192-201. doi: 10.5539/elt.v5n10p192.

Muchsonah (2015). Casting Critical Thinking In Critical Reading Instruction. Jurnal Sosioteknologi 14, 29-36. doi: http://dx.doi.org/10.5614/sostek.itbj.2015.14. 1.4 .

Muhajir, Bundu, P., and Ahmad, A. (2018). Inquiry Learning Strategy To Improve Students ' c ritical Thinking Skills. IOSR Journal of Research \& Method in Education (IOSR-JRME) 8, 42-46.

Nasrollahi, M. A., Krishnasamy, P. K. N., and Noor, N. M. (2014). Process of Implementing Critical Reading Strategies in an Iranian EFL Classroom: An Action Research. International Education Studies 8, 9-16. doi: 10.5539/ies.v8n1p9. yang dilakukan pun tidak sesuai dengan startegi-strategi semestinya berdasarkan karakteristik pembelajaran kritis oleh para pakar dan peneliti sebelumnya, dengan demikian kegiatan mengajar membaca pun cenderung kepada membaca biasa (reading aloud dan reading comprehension) untuk menjawab pertanyaan-pertanyaan berdasarkan teks yang telah disediakan.

\section{UCAPAN TERIMA KASIH}

Ucapan terima kasih dan penghargaan diberikan kepada Direktorat Riset dan Pengabdian Masyarakat Kementerian Riset, Teknologi, dan Pendidikan Tinggi yang telah memberikan dukungan penelitian ini.

Par, L. (2018). The Efl Students' Critical Reading Skills Across Cognitive Styles. JEELS (Journal of English Education and Linguistics Studies) 5, 73-96. doi: 10.30762/jeels.v5i1.541.

Rohmah, G. N. (2018). Critical Reading: Students' Problems, Strategies, and Reflections. J-ELLiT(Journal of English Language, Literature, and Teaching 2, 21-26.

Sugiyono (2018). Penelitian Kuantitatif Kualitatif dan R\&D (Bandung: Alfabeta), $1-380$.

Sulaiman, N. L. (2012). Incorporating Critical Thinking : Teaching Strategies in Malaysian Technical and Vocational Education Programs. https:// mountainscholar.org/handle/10217/71592.

Taglieber, L. K. (2000). Critical reading and critical thinking The State of the Art. Ilha Do Desterro A Journal of English Language. Literatures in English and Cultural Studies 1, 15-037. doi: https://doi.org/10.5007/\%25x.

Thamrin, N. R., Widodo, P., and Margana (2019). Developing Higher Order Thinking Skills (Hots) For Reading Comprehension Enhancement. Journal of Physics: Conference Series 1179, 012073-012073. doi: 10.1088/1742-6596/1179/ $1 / 012073$.

Wallace, C. (2003). Critical Reading in Language Education (London: Palgrave Macmillan), 1-201. doi: https://doi.org/10.1057/9780230514447.

Yousefi, S. and Mohammadi, M. (2016). Critical Thinking and Reading Comprehension among Postgraduate Students: The Case of Gender and Language Proficiency Level. Journal of Language Teaching and Research 7, 802-802. doi: 10.17507/jltr.0704.23.

Conflict of Interest Statement: The authors declare that the research was conducted in the absence of any commercial or financial relationships that could be construed as a potential conflict of interest.

Copyright (c) 2021 Hakim, Purwaningsih and Rachmawati. This is an open-access article distributed under the terms of the Creative Commons Attribution License (CC BY). The use, distribution or reproduction in other forums is permitted, provided the original author(s) and the copyright owner(s) are credited and that the original publication in this journal is cited, in accordance with accepted academic practice. No use, distribution or reproduction is permitted which does not comply with these terms. 


\section{LIST OF TABLES}

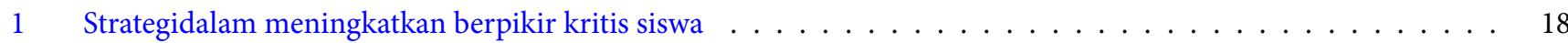

2 Strategidalam meningkatkan membaca kritis siswa 
TABLE 1 | Strategidalam meningkatkan berpikir kritis siswa

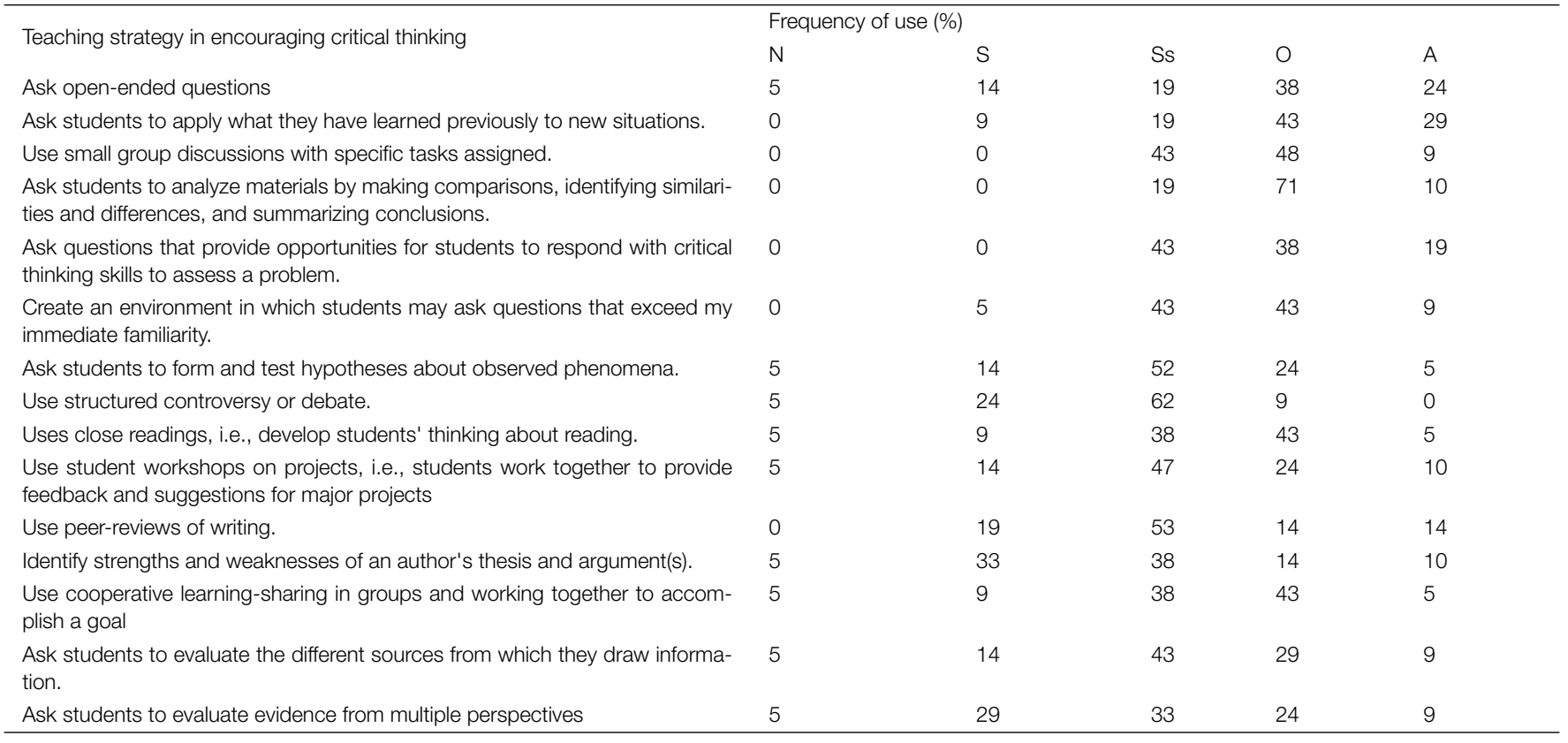


TABLE 2 | Strategidalam meningkatkan membaca kritis siswa

Teaching strategy in encouraging critical reading

Ask students to previewing (Getting an overview of text structure, text cues, pictures, and personal experiences prior to reading a text)

Use skimming technique (finding the thesis)

Ask students to look for clues in the text, think about what those clues trigger in prior knowledge, and make a prediction.

Ask students to monitor for understanding by checking to see if the text makes sense 0 Ask students to write a paragraph or more that presents the main ideas in their own words. 0 Restate and clarify the meaning of a few sentences from the text.

Ask students to combine ideas and information selected from different texts.

Ask students to write questions for every paragraph of the texts.

Invite students to abstract from their observations, to think about the implication of their ideas, and to generate these ideas across a range of specific contexts

Use writing assignments with specific tasks or goals focusing on a particular kind of thinking or reflection
Frequency of use (\%)

$\mathrm{N}$

0

S

10

Ss

52

O

24

A

0

0

48

33

43

5

43

43

43

0

33

29

14

24

14

52
19

9

10

14

24

10

19

5

10 